\title{
Inhibitor for protein disulfide-isomerase family A member 3 enhances the antiproliferative effect of inhibitor for mechanistic target of rapamycin in liver cancer: An in vitro study on combination treatment with everolimus and $16 \mathrm{~F} 16$
}

\author{
YOHEI KANEYA $^{1,2}$, HIDEYUKI TAKATA ${ }^{2}$, RYUICHI WADA ${ }^{1,3}$, SHOKO KURE $^{1,3}$, \\ KOUSUKE ISHINO $^{1}$, MITSUHIRO KUDO ${ }^{1}$, RYOTA KONDO ${ }^{2}$, NOBUHIKO TANIAI ${ }^{4}$, \\ RYUJI OHASHI ${ }^{1,3}$, HIROSHI YOSHIDA ${ }^{2}$ and ZENYA NAITO ${ }^{1,3}$
}

\author{
Departments of ${ }^{1}$ Integrated Diagnostic Pathology, and ${ }^{2}$ Gastrointestinal and Hepato-Biliary-Pancreatic Surgery, \\ Nippon Medical School; ${ }^{3}$ Department of Diagnostic Pathology, Nippon Medical School Hospital, Tokyo 113-8602; \\ ${ }^{4}$ Department of Gastrointestinal and Hepato-Biliary-Pancreatic Surgery, \\ Nippon Medical School Musashi Kosugi Hospital, Tokyo 211-8533, Japan
}

Received April 16, 2020; Accepted October 28, 2020

DOI: $10.3892 / \mathrm{ol} .2020 .12289$

\begin{abstract}
TOR is involved in the proliferation of liver cancer. However, the clinical benefit of treatment with mTOR inhibitors for liver cancer is controversial. Protein disulfide isomerase A member 3 (PDIA3) is a chaperone protein, and it supports the assembly of mTOR complex 1 (mTORC1) and stabilizes signaling. Inhibition of PDIA3 function by a small molecule known as 16F16 may destabilize mTORC1 and enhance the effect of the mTOR inhibitor everolimus (Ev). The aim of the present study was to elucidate the usefulness of combination treatment with Ev and 16F16 in liver cancer using cultured Li-7 and HuH-6 cells. The proliferation of cultured cells was examined following treatment with $0.01 \mu \mathrm{M} \mathrm{Ev}$, $2 \mu \mathrm{M} 16 \mathrm{~F} 16$ or both. The expression levels and phosphorylation of S6 kinase (S6K) and 4E-binding protein 1 (4E-BP1) were examined by western blotting. Li-7 was susceptible to Ev, and proliferation was reduced to $69.5 \pm 7.2 \%$ by Ev compared with that of untreated cells. Proliferation was reduced to
\end{abstract}

Correspondence to: Dr Yohei Kaneya, Department of Integrated Diagnostic Pathology, Nippon Medical School, 1-1-5 Sendagi, Bunkyo-ku, Tokyo 113-8602, Japan

E-mail: kaneyayohei1298@nms.ac.jp

Abbreviations: 4E-BP1, 4E-binding protein 1; Ev, everolimus; HCC, hepatocellular carcinoma; mTOR, mechanistic target of rapamycin; mTORC1, mTOR complex 1; PBS, phosphate-buffered saline; PDIA3, protein disulfide isomerase A member 3; RT-qPCR, reverse transcription-quantitative polymerase chain reaction; S6K, S6 kinase; TSC2, tuberous sclerosis complex 2; VEGF, vascular endothelial growth factor

Key words: mechanistic target of rapamycin, S6 kinase, eukaryotic elongation factor 4 binding protein, vascular endothelial growth factor
$90.2 \pm 10.8 \%$ by $16 \mathrm{~F} 16$ but to $62.3 \pm 12.2 \%$ by combination treatment with Ev and 16F16. HuH-6 cells were resistant to Ev, and proliferation was reduced to $86.7 \pm 6.1 \%$ by $\mathrm{Ev}$ and $86.6 \pm 4.8 \%$ by $16 \mathrm{~F} 16$. However, combination treatment suppressed proliferation to $57.7 \pm 4.0 \%$. Phosphorylation of S6K was reduced by Ev in both Li-7 and HuH-6 cells. Phosphorylation of 4E-BP1 was reduced by combination treatment in both $\mathrm{Li}-7$ and $\mathrm{HuH}-6$ cells. Immunoprecipitation assays demonstrated that PDIA3 formed a complex with 4E-BP1 but not with S6K. The small molecule 16F16 increased susceptibility to Ev in cultured liver cancer cells, which are resistant to Ev. The inhibition was associated with reduction of 4E-BP1 phosphorylation, which formed a complex with PDIA3. Combination treatment with Ev and 16F16 could be a novel therapeutic strategy for liver cancer.

\section{Introduction}

Liver cancer is the third leading causes of cancer death in the world (1). Early detection of liver cancer is difficult and most of cases are diagnosed at an advanced stage. Surgical resection is the primary treatment for liver cancer, and in some cases, liver cancer is treated with chemotherapy, transcatheter arterial chemoembolization, and radiofrequency ablation (2-5). The prognosis of liver cancer is not favorable even after complete surgical resection.

There are multiple mechanisms for carcinogenesis of liver cancer (6). Mechanistic target of rapamycin (mTOR) is a serine/threonine kinase, which regulates cell proliferation, cell death, metabolism and expression of growth factors (Fig. 1A) (7-10). mTOR is overexpressed in approximately $40 \%$ of liver cancer, and liver cancer with overexpression of mTOR follows an unfavorable clinical course (11). Preclinical studies showed that inhibition of the mTOR pathway suppress the development of liver cancer (12-16). However, clinical trials of mTOR inhibitors 
in liver cancer did not demonstrate significant improvement of survival (17). Subpopulation analysis of a clinical trial of everolimus (Ev) suggested that liver cancer without the expression of tuberous sclerosis complex 2 (TSC2), which suppresses mTOR complex 1 (mTORC1), is associated with susceptibility to Ev, and liver cancer with TSC2 expression was resistant to Ev (18). Alternatively, the activation of other signaling pathways such as mitogen-activated protein kinase (MAPK) and phosphatidylinositol-3 kinase (PI3K) has been suggested (6). A novel strategy is awaited to improve the effect of mTOR inhibitor and the prognosis of patients of liver cancer.

Protein disulfide isomerase (PDI) is a chaperone protein that supports the folding of synthesized proteins (19). PDIs have also been shown to be involved in multiple cellular functions such as degradation of protein, antigen processing, stabilization of receptors and intracellular signaling, and cell death (20). PDIs are involved in cellular functions in carcinoma cells. In liver cancer, a molecule of the PDI family, PDI A member 3 (PDIA3), which is known as GRP58 or ERp57, is highly expressed (21). The prognosis of liver cancer with a high PDIA3 expression level is worse than that of liver cancer with a low expression level.

PDIA3 is involved in the assembly and stability of signaling molecules such as mTOR and STAT3 $(19,22)$. It has been shown that PDIA3 forms a complex with mTORC1 and stabilizes the signaling pathway (23). The knock-down of PDIA3 reduced the phosphorylation activity of mTORC1, whereas overexpression enhanced the activity. It is thus plausible that inhibition of PDIA3 function destabilizes mTORC1 and attenuates its signaling activity. $16 \mathrm{~F} 16$ is a small compound that inhibits the function of PDIs (24). It is expected that the suppression of the PDIA3 function by 16F16 destabilizes the assembly of mTORC1 and increases the effect of mTOR inhibitor against liver cancer.

The aim of the present study is to explore whether PDIA3 inhibitor could increase the antiproliferative effect of Ev in liver cancer. The effect was investigated in 2 cultured liver cancer cell lines; i.e., Li-7, which lacks TSC 2 expression and is susceptible to $\mathrm{Ev}$, and $\mathrm{HuH}-6$, which expresses TSC2 and is resistant to $\mathrm{Ev}$ (18). Using these cultured cell lines, the effects of Ev and 16F16 on cell proliferation and phosphorylation of molecules in the mTOR signaling pathway were investigated. The expression of vascular endothelial growth factor (VEGF), which is essential for the formation of blood vessels in liver cancer (25), was also examined.

\section{Materials and methods}

Cell lines and culture. Cultured human liver cancer cell lines, Li-7 and HuH-6, were obtained from RIKEN BioResource Center, and Japanese Collection of Research Bioresources, respectively. Li-7 was derived from hepatocellular carcinoma (HCC) (26), and HuH-6 was derived from hepatoblastoma (27). The cells were cultured in RPMI-1640 (Thermo Fisher Scientific, Inc.) supplemented with $10 \%$ fetal bovine serum (Nichirei Biosciences, Inc.) at $37^{\circ} \mathrm{C}$.

Viability assay. Cultured cells were plated in 96-well plates at a density of $3 \times 10^{3}$ cells/well and cultured at $37^{\circ} \mathrm{C}$ for $24 \mathrm{~h}$. Ev, an inhibitor of mTOR (Cell Signaling Technology, Inc.), and 16F16, an inhibitor of PDIs (Enzo Life Sciences, Inc.), were then added to the culture medium, and the cells were cultured at $37^{\circ} \mathrm{C}$ for 72 h. Viable cells were determined using Cell Counting Kit- 8 (Dojindo Molecular Technologies, Inc.). Ten microliters CCK-8 solution containing 2-(2-methoxy-4-nitrophenyl)-3-(4-nitrophen yl)-5-(2,4-disulfophenyl)-2H-tetrazolium, monosodium salt was added to each well and incubated at $37^{\circ} \mathrm{C}$ for $2 \mathrm{~h}$. The absorbance at $450 \mathrm{~nm}$ was measured using an iMark Microplate Reader (Bio-Rad Laboratories, Inc.). Experiments were performed in triplicate. Cell viability was calculated as the percentage of viable cells treated with 16F16 and/or Ev compared with untreated cells.

Proliferation assay. Cultured cells were plated in 96-well plates at a density of $3 \times 10^{3}$ cells/well and cultured at $37^{\circ} \mathrm{C}$ for $24 \mathrm{~h}$. Then, $0.01 \mu \mathrm{M} \mathrm{Ev}$ and $2 \mu \mathrm{M} 16 \mathrm{~F} 16$ were added to the culture medium, and the cells were cultured at $37^{\circ} \mathrm{C}$. Viable cells were determined using Cell Counting Kit-8 at 0, 24, 48, and $72 \mathrm{~h}$. Experiments were performed in triplicate. Viable cells were indicated by absorbance at $450 \mathrm{~nm}$.

Preparation of protein samples. Cultured cells were plated in $100-\mathrm{mm}$ dishes at a density of $1.0 \times 10^{6}$ cells/dish and cultured at $37^{\circ} \mathrm{C}$ for $24 \mathrm{~h}$. Then, $0.01 \mu \mathrm{M} \mathrm{Ev}$ and $2 \mu \mathrm{M} 16 \mathrm{~F} 16$ were added to culture medium, and the cells were cultured at $37^{\circ} \mathrm{C}$ for $72 \mathrm{~h}$. After 3 washes with phosphate buffered saline (PBS), the cells were lysed in $50 \mathrm{mM}$ Tris- $\mathrm{HCl}(\mathrm{pH} 7.6) / 0.5 \%$ SDS and sonicated for $20 \mathrm{~min}$. The protein concentration was quantified using Pierce $660 \mathrm{~nm}$ Protein Assay Reagent (Thermo Fisher Scientific, Inc.), and protein samples were used for western blot analysis.

Immunoprecipitation (IP) analysis. Cultured HuH-6 cells were plated in $100-\mathrm{mm}$ dishes at a density of $1.0 \times 10^{6}$ cells/dish and cultured at $37^{\circ} \mathrm{C}$ for $72 \mathrm{~h}$. After washing with PBS, cells were lysed with IP Lysis Buffer (cat. no. 87787; Thermo Fisher Scientific, Inc.) with protease inhibitor cocktail (cat. no. P8340; dilution, 1:100; Sigma-Aldrich; Merck KGaA), and incubated on ice for $10 \mathrm{~min}$. The lysate was then collected with a scraper and transferred to a $1.5-\mathrm{ml}$ tube. The lysate was centrifuged at $12,000 \mathrm{x} \mathrm{g}$ at $4^{\circ} \mathrm{C}$ for $5 \mathrm{~min}$ and the supernatant was transferred to a new $1.5 \mathrm{ml}$ tube. The protein concentration was quantified using Pierce $660 \mathrm{~nm}$ Protein Assay Reagent.

Immunoprecipitation was done in a solution containing $500 \mu \mathrm{g}$ protein, Protein A/G PLUS-Agarose (cat. no. 6200, Santa Cruz Biotechnology, Inc.), and antibodies listed in Table I or isotype mouse IgG1 or rabbit IgG (cat. nos. 5415 and 3900; dilution 1:100; both from Cell Signaling Technology, Inc.) in $500 \mu 1$ IP Lysis Buffer with protease inhibitor cocktail at $4^{\circ} \mathrm{C}$ overnight. The mixture was applied to Sigma Prep Spin Columns with Break-Away Tips (Sigma-Aldrich; Merck KGaA), and the columns were washed with $500 \mu 1$ IP Lysis Buffer 3 times. Then, $30 \mu$ of Laemmli Sample Buffer (Bio-Rad Laboratories, Inc.) with 3-mercaptethanol was loaded into the columns, and the columns were incubated at $95^{\circ} \mathrm{C}$ for $5 \mathrm{~min}$. Protein samples were retrieved by centrifugation at $100 \mathrm{x} \mathrm{g}$ for $3 \mathrm{~min}$ and the samples were used for western blot analysis.

Western blot analysis. Protein samples were electrophoresed in $5-20 \%$ polyacrylamide gel (e-PAGEL; ATTO Corp.) and transferred onto a polyvinylidene difluoride membrane. After 
Table I. List of antibodies used in the present study.

Dilution

\begin{tabular}{llrr}
\cline { 2 - 3 } Antibody & Cat. no. & \multicolumn{1}{c}{ Company } & WB \\
\hline PDIA3 & ab13506 & Abcam & $1: 2,000$ \\
TSC2 & 4308 & Cell Signaling Technology, Inc. & $1: 1,000$ \\
mTOR & 2972 & Cell Signaling Technology, Inc. & $1: 1,000$ \\
4E-BP1 & 9644 & Cell Signaling Technology, Inc. & $1: 1,000$ \\
p-4E-BP1 (Thr70) & 13396 & Cell Signaling Technology, Inc. & $1: 1,000$ \\
S6K & 9202 & Cell Signaling Technology, Inc. & $1: 1,000$ \\
p-S6K (Thr389) & 9234 & Cell Signaling Technology, Inc. & $1: 1,000$ \\
$\beta$-actin & A5316 & Sigma-Aldrich; Merck KGaA & $1: 100$ \\
& & & $1: 10,000$
\end{tabular}

IP, immunoprecipitation; WB, western blotting; PDIA3, protein disulfide isomerase A member 3; TSC2, tuberous sclerosis complex 2; 4E-BP1, 4E-binding protein 1; S6K, S6 kinase.

blocking with a mixture of $5 \%$ skim milk and Tris-buffered saline $/ 0.05 \%$ Tween-20 at room temperature for $1 \mathrm{~h}$, the membrane was incubated with antibodies listed in Table I at $4^{\circ} \mathrm{C}$ overnight. After washing with $25 \mathrm{mM}$ Tris- $\mathrm{HCl}$ (pH 8.0)/150 mM NaCl/0.01\% Triton X, the membranes were incubated with horseradish peroxidase-conjugated anti-mouse immunoglobulin antibody (True Blot, cat. no. 18-8817-33; dilution, 1:10,000; Rockland Inc.), anti-mouse immunoglobulin antibody (cat. no. A106PU; dilution, 1:10,000), or anti-rabbit immunoglobulin antibody (cat. no. A102PU; dilution, 1:10,000, both from American Qualex Scientific Products, Inc.) at room temperature for $1 \mathrm{~h}$. The peroxidase activity was detected as chemiluminescence using SuperSignal West Dura Extended Duration Substrate (Thermo Fisher Scientific, Inc.). Positive bands were quantified using Quantity One Software version 4.6.2 (Bio-Rad Laboratories, Inc.). Protein expression and phosphorylation were normalized to the expression of $\beta$-actin, and the levels in treated cells were expressed as fold-change relative to untreated cells.

Reverse transcription-quantitative polymerase chain reaction $(R T-q P C R)$. Cells were plated on $60-\mathrm{mm}$ dishes at $1.0 \times 10^{6}$ cells/well and cultured at $37^{\circ} \mathrm{C}$ for $24 \mathrm{~h}$. Then, $0.01 \mu \mathrm{M}$ Ev and/or $2 \mu \mathrm{M} 16 \mathrm{~F} 16$ were added to culture medium and the cells were cultured at $37^{\circ} \mathrm{C}$ for $72 \mathrm{~h}$. After a wash with PBS, total RNA was extracted using TRIzol (Thermo Fisher Scientific, Inc.) according to the recommended protocol. The concentration of total RNA was measured using NanoDrop (Thermo Fisher Scientific, Inc.).

Total RNA (200 ng) was treated with DNase I (Thermo Fisher Scientific, Inc.) at room temperature for $15 \mathrm{~min}$. cDNA was reverse-transcribed from total RNA using a SuperScript VILO cDNA Synthesis Kit (Thermo Fisher Scientific, Inc.) according to the manufacturer's protocols. Quantitative PCR was performed in a $20-\mu 1$ reaction mixture containing 1X TaqMan Fast Universal PCR Master Mix (Thermo Fisher Scientific, Inc.), 1X TaqMan primers and probes and reverse-transcribed cDNA. The TaqMan primers and probes were as follows: vascular endothelial growth factor (VEGF) (Hs00900055_m1) and 18S ribosome
RNA (rRNA) (Hs03928990) (all from Thermo Fisher Scientific, Inc.). The reaction was initiated with incubation at $95^{\circ} \mathrm{C}$ for $20 \mathrm{sec}$, followed by 40 cycles of incubation at $95^{\circ} \mathrm{C}$ for $1 \mathrm{sec}$ and at $60^{\circ} \mathrm{C}$ for $20 \mathrm{sec}$. Alterations in fluorescence were monitored using the Step One Plus Real-Time PCR System (Thermo Fisher Scientific, Inc.). The expression level of VEGF was standardized with that of $18 \mathrm{~S}$ rRNA. The expression levels were calculated by the $2^{-\Delta \Delta \mathrm{Cq}}$ method (28).

Statistical analysis. All statistical analyses were performed using R software. The half maximal-inhibitory concentration $\left(\mathrm{IC}_{50}\right)$ was calculated as the estimated value \pm standard error. All other data were expressed as mean \pm standard deviation. Comparison of data between 2 groups was performed using Mann-Whitney $U$ test. Three or more groups were conducted by Kruskal-Wallis test followed by Dunn's post-hoc test. $\mathrm{P}<0.05$ was considered to indicate statistical significance.

\section{Results}

Expression of molecules in cultured cells. Expression of TSC2 was not detected in Li-7 cells, whereas TSC2 was expressed in HuH-6 cells (Fig. 1B). The expression of mTOR, S6 kinase (S6K), 4E-binding protein 1 (4E-BP1), and PDIA3 was noted in both HuH-6 and Li-7 cells, and their expression levels appeared comparable between the 2 lines.

Viability of cultured cells treated with everolimus and 16 F16. Li-7 cells were susceptible to Ev, and HuH-6 cells were resistant to Ev (Fig. 2A). Treatment with $0.01 \mu \mathrm{M}$ Ev inhibited viability to $54.0 \pm 5.0 \%$ in $\mathrm{Li}-7$ cells, but only to $97.8 \pm 5.0 \%$ in HuH- 6 cells. The $\mathrm{IC}_{50}$ of Ev was $0.02 \pm 0.01 \mu \mathrm{M}$ in Li-7 cells and 9.26 $\pm 4.44 \mu \mathrm{M}$ in HuH-6 cells. It was shown that high concentration of $16 \mathrm{~F} 16$ reduces the viability of culture liver cancer cells. Susceptibility to $16 \mathrm{~F} 16$ was, however, comparable between Li-7 and HuH-6 cells (Fig. 2B). The $\mathrm{IC}_{50}$ of $16 \mathrm{~F} 16$ was $5.27 \pm 0.16$ and $5.05 \pm 0.12 \mu \mathrm{M}$ in Li-7 and HuH-6 cells, respectively.

Susceptibility in Li-7 cells and resistance in HuH-6 cells to Ev was comparable with a previous report (18). The difference 

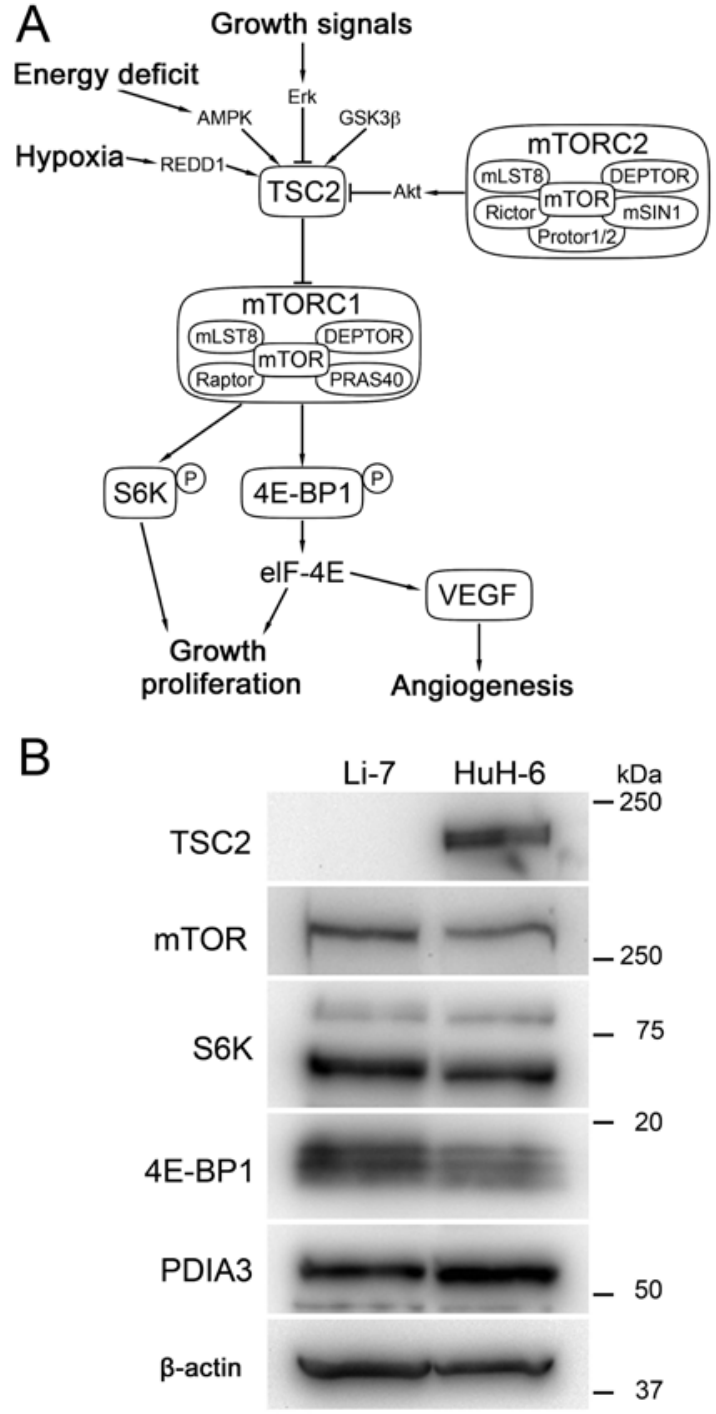

Figure 1. mTOR signaling pathway and expression of molecules in cultured cells. (A) Schematic of the mTOR signaling pathway. (B) Expression levels of molecules in the mTOR signaling pathway in $\mathrm{Li}-7$ and $\mathrm{HuH}-6$ cells. TSC2, tuberous sclerosis complex 2; S6K, S6 kinase; 4E-BP1, 4E-binding protein 1; PDIA3, protein disulfide isomerase A member 3.

in the cell viability by Ev between Li-7 and HuH- 6 was evident at $0.01 \mu \mathrm{M}$. Although $16 \mathrm{~F} 16$ reduced the cell viability at high concentration, the susceptibility was same in $\mathrm{Li}-7$ and $\mathrm{HuH}-6$ cells. At low concentration of $2 \mu \mathrm{M} 16 \mathrm{~F} 16$, the viability was suppressed only to $98.2 \pm 8.6 \%$ in Li-7 cells and $98.1 \pm 2.4 \%$ in $\mathrm{HuH}-6$ cells. It was considered that at this concentration, 16F16 did not show a significant cytotoxic effect in either cell line. Depending on these evidences, the subsequent experiments were performed under treatment with $0.01 \mu \mathrm{M}$ Ev alone, $2 \mu \mathrm{M}$ $16 \mathrm{~F} 16$ alone, and a combination of $0.01 \mu \mathrm{M} \mathrm{Ev}$ and $2 \mu \mathrm{M} 16 \mathrm{~F} 16$.

Effect of combination treatment with everolimus and 16F16 on cultured cells. Li-7 cells treated with Ev alone appeared less viable at $72 \mathrm{~h}$ compared with untreated Li-7 cells (Fig. 3A). 16 F16 did not appear to affect viability. Cultured cell treated with Ev and 16F16 appeared less viable. Conversely, HuH-6 cells appeared viable at $72 \mathrm{~h}$ when treated with Ev alone or 16F16 alone (Fig. 3B). Cultured cells treated with Ev and 16 F16 in combination appeared to be less viable.
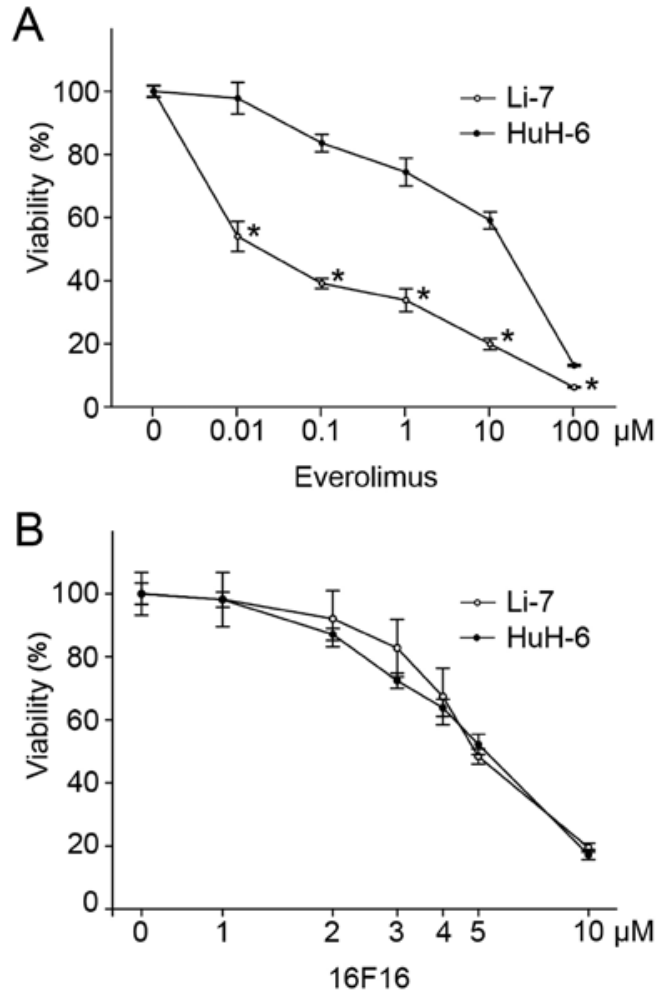

Figure 2. Susceptibility of cultured cells to everolimus and $16 \mathrm{~F} 16$. (A) Susceptibility of Li-7 and HuH-6 cells to everolimus. (B) Susceptibility of Li-7 and HuH-6 cells to $16 \mathrm{~F} 16$. ${ }^{*} \mathrm{P}<0.05$ vs. HuH-6 (Mann-Whitney U test).

Proliferation of Li-7 cells was significantly reduced to $69.5 \pm 7.2 \%$ by treatment with Ev alone compared with untreated Li-7 cells at $72 \mathrm{~h}$ (Fig. 3C). Proliferation was reduced to $90.2 \pm 10.8 \%$ by treatment with $16 \mathrm{~F} 16$ but was significantly suppressed to $62.3 \pm 12.2 \%$ by combination treatment with Ev and 16F16. In HuH-6 cells, proliferation was reduced to $86.7 \pm 6.1 \%$ by $\mathrm{Ev}$ alone and $86.6 \pm 4.8 \%$ by $16 \mathrm{~F} 16$ alone, whereas proliferation was significantly inhibited to $57.7 \pm 4.0 \%$ by combination treatment with Ev and 16F16 (Fig. 3D).

Expression and phosphorylation of molecules of the mTOR signaling pathway. The expression and phosphorylation state of S6K and 4E-BP1, which are downstream molecules in mTORC1 signaling pathway, were analyzed by western blot. In Li-7 cells, the expression of S6K was slightly decreased by treatment with Ev or 16F16 and by the Ev and 16F16 in combination, as compared with untreated cells (Fig. 4A). p-S6K was reduced by treatment with Ev. Treatment with 16F16 slightly reduced S6K phosphorylation, and p-S6K was reduced by combination treatment with Ev and 16F16. The expression of 4E-BP1 appeared to be reduced in treated cells. p-4E-BP1 appeared to be slightly reduced in cells treated with Ev alone and 16F16 alone. The phosphorylation of $4 \mathrm{E}-\mathrm{BP} 1$ was reduced by combination treatment with Ev and 16F16 (Fig. 4A). In HuH-6 cells, the expression of S6K was slightly elevated in treated cells. p-S6K was reduced in cells treated with Ev alone. Phosphorylation was not inhibited by treatment with $16 \mathrm{~F} 16$, but it was reduced by the combination treatment. Expression of 4E-BP1 was slightly elevated in treated cells. Expression of p-4E-BP1 was comparable between treatment with Ev alone and 16F16 alone, whereas 

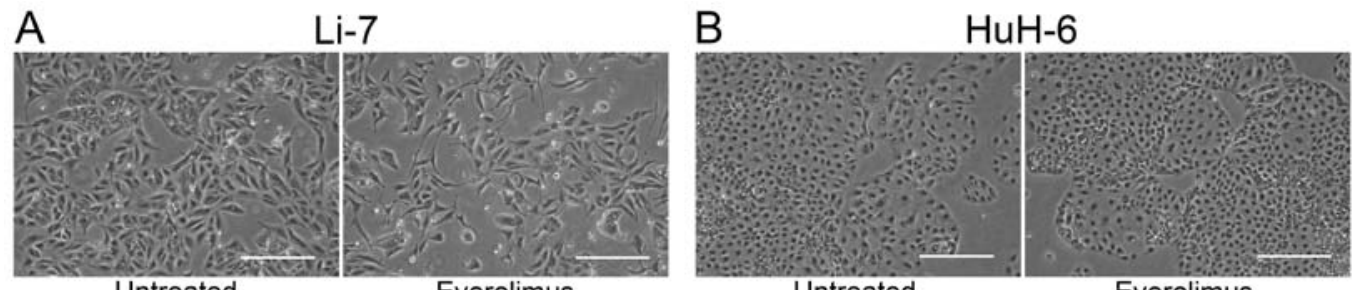

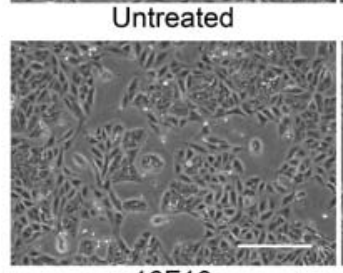

$16 \mathrm{~F} 16$

C

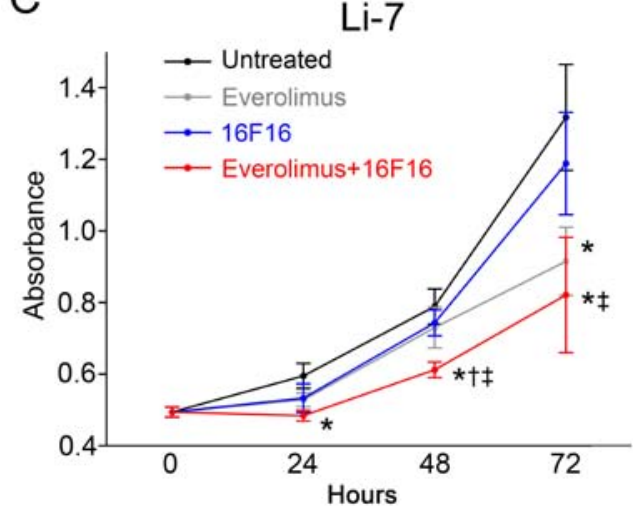

Everolimus

Everolimus+16F16
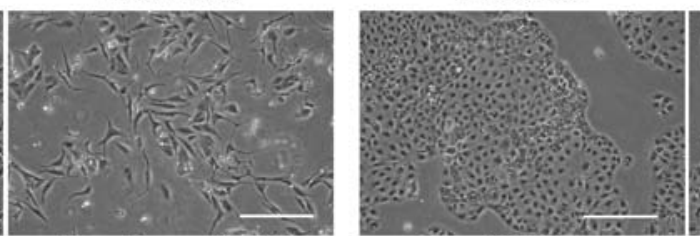

$16 \mathrm{~F} 16$

D

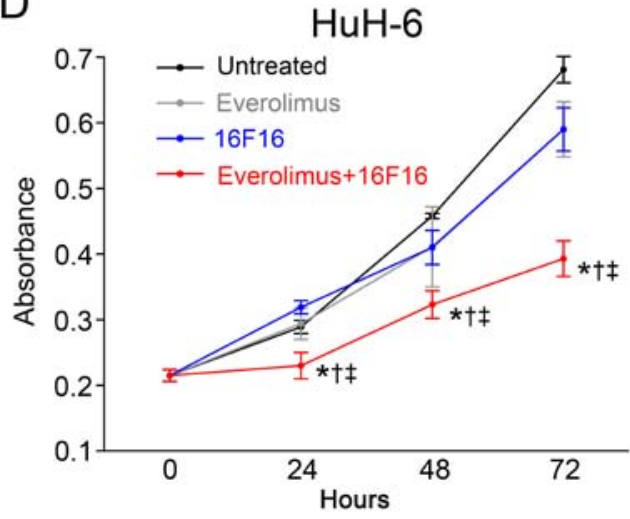

Figure 3. Cultured cells treated with everolimus and 16F16. Microscopic appearance of treated cultured (A) Li-7 and (B) HuH-6 cells. Scale bar, $100 \mu \mathrm{m}$. Proliferation of cultured (C) Li-7 and (D) HuH-6 cells. ${ }^{*} \mathrm{P}<0.05$ vs. untreated; ${ }^{\dagger} \mathrm{P}<0.05$ vs. everolimus; ${ }^{\dagger} \mathrm{P}<0.05$ vs. $16 \mathrm{~F} 16$ (Kruskal Wallis test followed by Dunn's post hoc test).

phosphorylation was reduced by the combination treatment (Fig. 4B).

Immunoprecipitation analysis. Whether PDIA3 forms a complex with S6K and 4E-BP1 was examined by immunoprecipitation using $\mathrm{HuH}-6$ cell lysates. In the sample immunoprecipitated with anti-PDIA3 antibody, no positive band was observed in western blots with anti-S6K antibody (Fig. 5A). No positive band was detected in western blotting with anti-PDIA3 antibody in the sample immunoprecipitated with anti-S6K antibody (Fig. 5A). On the other hand, in the sample immunoprecipitated with anti-PDIA3 antibody, a positive band was detected in western blotting with anti-4E-BP1 antibody (Fig. 5B). Immunoprecipitated PDIA3 was observed in western blotting with anti-PDIA3 antibody in the sample immunoprecipitated with anti-4E-BP1 antibody (Fig. 5B). The immunoprecipitation analysis demonstrated complex formation of PDIA3 with 4E-BP1 but not with S6K.

VEGF expression in cultured cells. mTORC1 signaling regulates the expression of VEGF, which plays an important role in angiogenesis and the growth of liver cancer. VEGF mRNA expression was examined in cultured cells by RT-PCR. In Li-7 cells, the expression of VEGF mRNA was reduced to $44.1 \pm 4.9$ and $47.5 \pm 2.4 \%$ of untreated cells by treatment with Ev alone and by combination treatment with Ev and 16F16, respectively (Fig. 6A). In contrast, VEGF mRNA expression was roughly comparable among $\mathrm{HuH}-6$ cells, and there was no apparent alteration by Ev or 16F16 (Fig. 6B).

\section{Discussion}

This is the first study to show enhancement of the antiproliferative effect of inhibitor for mTOR by inhibitor for PDIA3 in liver cancer. Two cell lines of liver cancer, one susceptible and one resistant to mTOR inhibitor, were used in the present study. Combination treatment with Ev and 16F16 suppressed the proliferation of cultured liver cancer cells, and the suppression was associated with reduced phosphorylation of 4E-BP1, which formed a complex with PDIA3. It is noteworthy that enhancement was evident in a cultured liver cancer cell that was resistant to mTOR inhibitor.

It is thought that the activation of mTOR is associated with the pathogenesis and aggressiveness of liver cancer. In vitro and animal studies have shown that mTOR inhibitors could be effective for the treatment of liver cancer $(11,13,15,29)$. However, clinical trials have failed to demonstrate significant improvement in the prognosis in of patients with liver cancer (17). To date, no mTOR inhibitors have been approved for the treatment of liver cancer. This may be due in part to the incomplete inhibition of mTOR and the activation of other signaling pathways such as MAPK and PI3K by feedback mechanism (30). Subpopulation analysis of liver cancer treated with Ev suggested that liver cancer with loss of TSC2 is susceptible to Ev, but liver cancer with the expression of 


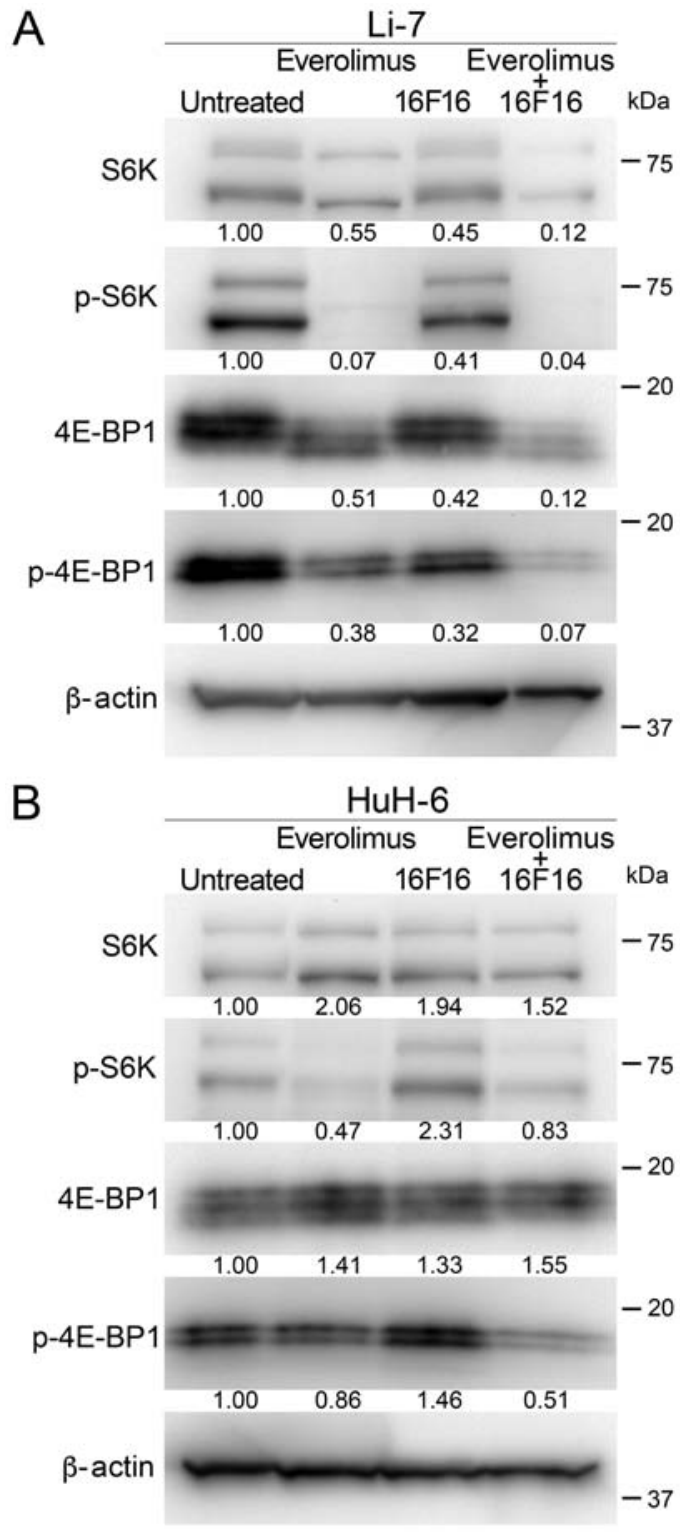

Figure 4. Expression levels and phosphorylation of molecules in cultured (A) Li-7 and (B) HuH-6 cells. The numbers represent the fold-change in expression and phosphorylation levels in treated vs. untreated cells. S6K, S6 kinase; 4E-BP1, 4E-binding protein 1; p-, phosphorylated.

TSC2 is resistant to Ev. To overcome the incomplete effect of mTOR inhibitors for liver cancer, combination therapies have been utilized. Concomitant inhibition of mTOR and MAPK or DNA replication was shown to possibly be effective for the treatment of liver cancer (31-33).

The association of PDIA3 with mTOR was shown in a previous study by Ramirez-Rangel and colleagues (23). It was demonstrated that knock-down of PDIA3 by specific siRNA suppressed the proliferation, while overexpression enhanced proliferation, and cell proliferation was correlated with phosphorylation of S6K and 4E-BP1. It was also shown that PDIA3 forms a complex with mTORC1 but not with mTORC2 (23). 16F16 may have an effect similar to that of siRNA for PDIA3, since a high concentration of $16 \mathrm{~F} 16$ reduced the cell viability and proliferation of cultured liver cancer cells. However, enhancement of the antiproliferative effect of Ev by $16 \mathrm{~F} 16$ was achieved at a suboptimal concentration of $16 \mathrm{~F} 16$, at which
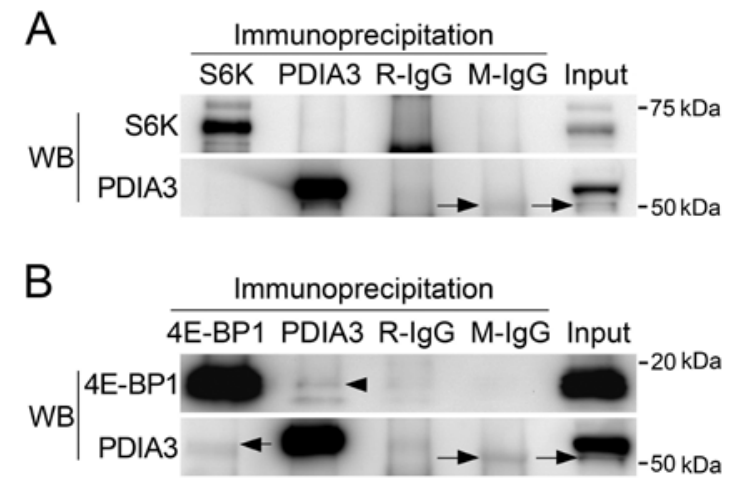

Figure 5. Immunoprecipitation assay using (A) anti-S6K and anti-PDIA3 antibodies and (B) anti-4E-BP1 and anti-PDIA3 antibodies. The arrowhead indicates a band immunoprecipitated by anti-PDIA 3 in western blotting with anti-4E-BP1 antibody. The short arrow indicates a band immunoprecipitated by anti-4E-BP1 antibody in western blotting with anti-PDIA3 antibody. Non-specific bands of immunoglobulin have been indicated (long arrows). S6K, S6 kinase; 4E-BP1, 4E-binding protein 1; PDIA3, protein disulfide isomerase A member 3; WB, western blotting.
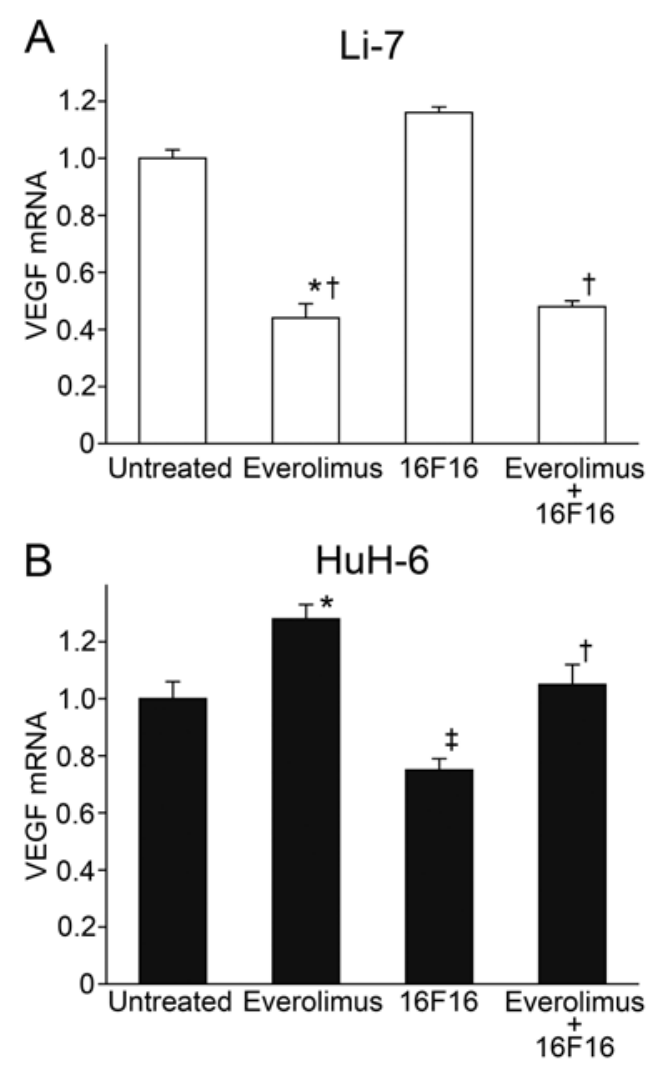

Figure 6. Expression levels of VEGF mRNA in cultured (A) Li-7 and (B) HuH- 6 cells. ${ }^{*} \mathrm{P}<0.05$ vs. untreated; ${ }^{+} \mathrm{P}<0.05$ vs. $16 \mathrm{~F} 16$; ${ }^{\dagger} \mathrm{P}<0.05$ vs. everolimus $+16 \mathrm{~F} 16$ (Kruskal Wallis test followed by Dunn's post hoc test). VEGF, vascular endothelial growth factor.

cellular viability was not affected. Although the phosphorylation of S6K was inhibited by Ev alone, the phosphorylation of 4E-BP1 was reduced by combination treatment with Ev and 16F16. This may suggest that the mTOR-4E-BP1 signaling pathway is more affected by the integrity of the complex supported by PDIA3. This is accounted for by the formation of a complex of PDIA3 with 4E-BP1 but not with S6K, as shown in the immunoprecipitation assay. 
There was a difference in the association of cell proliferation with the phosphorylation of S6K and 4E-BP1 between Li-7 and HuH-6 cells, which were susceptible and resistant to Ev, respectively. Cell proliferation was inhibited by Ev alone in Li-7 cells, whereas proliferation was only inhibited by combination treatment with Ev and 16F16 in HuH-6 cells. This may be explained by the expression of TSC2, which is a molecule upstream of mTORC1 and inhibits mTOR function $(18,34)$. Thus, molecular analysis of TSC2 expression may be useful to determine cases that can benefit most from combination treatment with Ev and 16F16. However, there could be a difference in the mechanism of pathogenesis between cultured liver cancer cell lines. It may be also accounted for by the origin of the cultured cells; Li-7 was derived from HCC, and Huh- 6 was derived from hepatoblastoma. It is plausible that the inhibition of proliferation is a synergistic effect due to mTOR inhibition and an unknown molecule involved in the pathogenesis by 16F16. The further investigation on the pathogenesis of liver cancer is needed.

Angiogenesis plays an important role in the progression of liver cancer $(25,35)$. It has been shown that VEGF released from liver cancer initiates angiogenesis and vascular formation $(35,36)$. In the present study, VEGF expression was reduced by treatment with $\mathrm{Ev}$ in Li-7 cells but was unchanged by treatment with Ev and or Ev and 16F16 in combination in HuH-6 cells. For the treatment of liver cancer, which is resistant to $\mathrm{Ev}$, the combination of $\mathrm{Ev}$ and $16 \mathrm{~F} 16$ is effective for inhibiting proliferation but not sufficiently effective for inhibiting angiogenesis. Anti-angiogenic therapy may therefore be needed as an adjunct to combination treatment with Ev and 16F16.

The present study was in vitro study using cultured liver cells. There are a couple of issues that needs to be addressed in the future study. 16F16 was used at the concentration, at which the viability of cultured liver cancer cells was not affected. However, the toxicity of 16F16 was not fully elucidated in vivo. Further, the effect of mTOR inhibitor for human liver cancer is controversial (17). Thus, the effect of combination treatment of Ev and 16F16 needs to be verified in animal model inoculated with cultured liver cancer cells. In liver cancer, the recurrence soon after the resection of the primary tumor is not infrequent. A novel therapy to prevent the survival and induction of cancer stem cell is expected. It is considered that mTORC1 signaling is involved in the development and maintenance of stem cells (37). Further study is needed to examine whether the combination treatment of Ev and 16F16 suppress the development of cancer stem cell of liver cancer.

It has been shown that the level of PDIA3 expression is associated with the prognosis of liver cancer (21). Liver cancer with high PDIA3 expression follows an unfavorable course and is characterized by high proliferation activity and a low frequency of cell death. The expression of PDIA3 and its association with prognosis has been reported for other carcinomas (21,22,38-41). Furthermore, knock-down of PDIA3 may enhance the effect of radiation therapy in laryngeal cancer (38) and breast cancer (42). The addition of a PDIA3 inhibitor may be beneficial to enhance the effect of chemotherapy and radiation therapy. PDIA3 may form a complex with other molecules that are involved in the carcinogenesis and behavior of tumors. Targeting of chaperone protein would be a novel strategy for enhancing the therapeutic effects of small molecule inhibitors, radiation, and chemotherapy.

\section{Acknowledgements}

The authors would like to acknowledge the assistance of Ms. Kiyoko Kawahara for cell culture, Mr. Takenori Fujii and Ms. Yoko Kawamoto for help with western blotting, and Mr. Kiyoshi Teduka for help with reverse transcription-quantitative PCR (all from Department of Integrated Diagnostic Pathology, Nippon Medical School, Tokyo, Japan).

\section{Funding}

No funding was received.

\section{Availability of data and materials}

All data generated or analyzed during this study are included in this published article.

\section{Authors' contributions}

YK, RW and ZN designed the study and wrote the manuscript draft. YK performed histological examinations. YK, HT and RO conducted biochemical examinations and data analyses. RW and SK performed statistical analyses. YK, KI, MK and NT conducted cell culture experiments and prepared figures/tables. YK, RK and HY performed RT-qPCR. HY and ZN supervised the experimental design and manuscript writing. All authors agree to be accountable for all aspects of the work in ensuring that questions related to the accuracy or integrity of any part of the work are appropriately investigated and resolved. All authors read and approved the final manuscript.

\section{Ethics approval and consent to participate}

Not applicable.

\section{Patient consent for publication}

Not applicable.

\section{Competing interests}

The authors declare that they have no competing interests.

\section{References}

1. Altekruse SF, McGlynn KA and Reichman ME: Hepatocellular carcinoma incidence, mortality, and survival trends in the United States from 1975 to 2005. J Clin Oncol 27: 1485-1491, 2009.

2. Eso Y and Marusawa H: Novel approaches for molecular targeted therapy against hepatocellular carcinoma. Hepatol Res 48: 597-607, 2018

3. Forner A, Reig $\mathrm{M}$ and Bruix J: Hepatocellular carcinoma. Lancet 391: 1301-1314, 2018.

4. Grandhi MS, Kim AK, Ronnekleiv-Kelly SM, Kamel IR, Ghasebeh MA and Pawlik TM: Hepatocellular carcinoma: From diagnosis to treatment. Surg Oncol 25: 74-85, 2016.

5. Yoshida H, Taniai N, Yoshioka M, Hirakata A, Kawano Y, Shimizu T, Ueda J, Takata H, Nakamura Y and Mamada Y: Current status of laparoscopic hepatectomy. J Nippon Med Sch 86: 201-206, 2019. 
6. SwamySG,KameshwarVH,ShubhaPB,LooiCY,Shanmugam MK, Arfuso F, Dharmarajan A, Sethi G, Shivananju NS and Bishayee A: Targeting multiple oncogenic pathways for the treatment of hepatocellular carcinoma. Target Oncol 12: 1-10, 2017.

7. Conciatori F, Ciuffreda L, Bazzichetto C, Falcone I, Pilotto S, Bria E, Cognetti F and Milella M: mTOR Cross-talk in cancer and potential for combination therapy. Cancers (Basel) 10: 23, 2018.

8. Fasolo A and Sessa C: Targeting mTOR pathways in human malignancies. Curr Pharm Des 18: 2766-2777, 2012

9. Matter MS, Decaens T, Andersen JB and Thorgeirsson SS Targeting the mTOR pathway in hepatocellular carcinoma: Current state and future trends. J Hepatol 60: 855-865, 2014.

10. Tian T, Li X and Zhang J: mTOR Signaling in cancer and mTOR inhibitors in solid tumor targeting therapy. Int J Mol Sci20: 755, 2019.

11. Villanueva A, Chiang DY, Newell P, Peix J, Thung S, Alsinet C, Tovar V, Roayaie S, Minguez B, Sole M, et al: Pivotal role of mTOR signaling in hepatocellular carcinoma. Gastroenterology 135 : 1972-1983, 1983.e1-11, 2008.

12. Buitrago-Molina LE, Pothiraju D,Lamlé J,Marhenke S, Kossatz U, Breuhahn K, Manns MP, Malek N and Vogel A: Rapamycin delays tumor development in murine livers by inhibiting proliferation of hepatocytes with DNA damage. Hepatology 50: 500-509, 2009.

13. Engl T, Rutz J, Maxeiner S, Juengel E, Roos F, Khoder W, Bechstein WO, Nelson K, Tsaur I, Haferkamp A, et al: mTOR inhibition reduces growth and adhesion of hepatocellular carcinoma cells in vitro. Mol Med Rep 16: 7064-7071, 2017.

14. Sahin F, Kannangai R, Adegbola O, Wang J, Su G and Torbenson M: mTOR and P70 S6 kinase expression in primary liver neoplasms. Clin Cancer Res 10: 8421-8425, 2004.

15. Semela D, Piguet AC, Kolev M, Schmitter K, Hlushchuk R, Djonov V, Stoupis C and Dufour JF: Vascular remodeling and antitumoral effects of mTOR inhibition in a rat model of hepatocellular carcinoma. J Hepatol 46: 840-848, 2007.

16. Thomas HE, Mercer CA, Carnevalli LS, Park J, Andersen JB Conner EA, Tanaka K, Matsutani T, Iwanami A, Aronow BJ, et al: mTOR inhibitors synergize on regression, reversal of gene expression, and autophagy in hepatocellular carcinoma. Sci Transl Med 4: 139ra84, 2012.

17. Zhu AX, Kudo M, Assenat E, Cattan S, Kang YK, Lim HY, Poon RT, Blanc JF, Vogel A, Chen CL, et al: Effect of everolimus on survival in advanced hepatocellular carcinoma after failure of sorafenib: The EVOLVE-1 randomized clinical trial. JAMA 312 57-67, 2014.

18. Huynh H,Hao HX, Chan SL, Chen D, Ong R, Soo KC, Pochanard P, Yang D, Ruddy D, Liu M, et al: Loss of tuberous sclerosis complex 2 (TSC2) is frequent in hepatocellular carcinoma and predicts response to mTORC1 inhibitor everolimus. Mol Cancer Ther 14: 1224-1235, 2015.

19. Turano C, Gaucci E, Grillo C and Chichiarelli S: ERp57/GRP58: A protein with multiple functions. Cell Mol Biol Lett 16: 539-563, 2011.

20. Hettinghouse A, Liu R and Liu CJ: Multifunctional molecule ERp57: From cancer to neurodegenerative diseases. Pharmacol Ther 181: 34-48, 2018.

21. Takata H, Kudo M, Yamamoto T, Ueda J, Ishino K, Peng WX, Wada R, Taniai N, Yoshida H, Uchida E, et al: Increased expression of PDIA3 and its association with cancer cell proliferation and poor prognosis in hepatocellular carcinoma. Oncol Lett 12: 4896-4904, 2016.

22. Kondo R, Ishino K, Wada R, Takata H, Peng WX, Kudo M, Kure S, Kaneya Y, Taniai N, Yoshida H, et al: Downregulation of protein disulfide isomerase A3 expression inhibits cell proliferation and induces apoptosis through STAT3 signaling in hepatocellular carcinoma. Int J Oncol 54: 1409-1421, 2019.

23. Ramírez-Rangel I, Bracho-Valdés I, Vázquez-Macías A, Carretero-Ortega J, Reyes-Cruz G and Vázquez-Prado J: Regulation of mTORC1 complex assembly and signaling by GRp58/ERp57. Mol Cell Biol 31: 1657-1671, 2011.

24. Hoffstrom BG, Kaplan A, Letso R, Schmid RS, Turmel GJ, Lo DC and Stockwell BR: Inhibitors of protein disulfide isomerase suppress apoptosis induced by misfolded proteins. Nat Chem Biol 6: 900-906, 2010.
25. Yang ZF and Poon RT: Vascular changes in hepatocellular carcinoma. Anat Rec (Hoboken) 291: 721-734, 2008.

26. Hirohashi S, Shimosato Y, Kameya T, Koide T, Mukojima T, Taguchi Y and Kageyama K: Production of alpha-fetoprotein and normal serum proteins by xenotransplanted human hepatomas in relation to their growth and morphology. Cancer Res 39: $1819-1828,1979$

27. Doi I: Establishment of a cell line and its clonal sublines from a patient with hepatoblastoma. Gan 67: 1-10, 1976

28. Livak KJ and Schmittgen TD: Analysis of relative gene expression data using real-time quantitative PCR and the 2(-Delta Delta $\mathrm{C}(\mathrm{T})$ ) method. Methods 25: 402-408, 2001

29. Huynh H, Chow KH, Soo KC, Toh HC, Choo SP, Foo KF, Poon D, Ngo VC and Tran E: RAD001 (everolimus) inhibits tumour growth in xenograft models of human hepatocellular carcinoma. J Cell Mol Med 13: 1371-1380, 2009.

30. Carracedo A, Ma L, Teruya-Feldstein J, Rojo F, Salmena L, Alimonti A, Egia A, Sasaki AT, Thomas G, Kozma SC, et al: Inhibition of mTORC1 leads to MAPK pathway activation through a PI3K-dependent feedback loop in human cancer. J Clin Invest 118: 3065-3074, 2008.

31. Newell P, Toffanin S, Villanueva A, Chiang DY, Minguez B, Cabellos L, Savic R, Hoshida Y, Lim KH, Melgar-Lesmes P, et al: Ras pathway activation in hepatocellular carcinoma and anti-tumoral effect of combined sorafenib and rapamycin in vivo. J Hepatol 51: 725-733, 2009.

32. Piguet AC, Saar B, Hlushchuk R, St-Pierre MV, McSheehy PM, Radojevic V, Afthinos M, Terracciano L, Djonov V and DufourJF: Everolimus augments the effects of sorafenib in a syngeneic orthotopic model of hepatocellular carcinoma. Mol Cancer Ther 10: 1007-1017, 2011.

33. Wang Z, Zhou J, Fan J, Qiu SJ, Yu Y, Huang XW and Tang ZY: Effect of rapamycin alone and in combination with sorafenib in an orthotopic model of human hepatocellular carcinoma. Clin Cancer Res 14: 5124-5130, 2008.

34. Ferrin G, Guerrero M, Amado V, Rodriguez-Peralvarez $M$ and De la Mata M: Activation of mTOR signaling pathway in hepatocellular carcinoma. Int J Mol Sci 21: 1266, 2020.

35. Liu K, Zhang X, Xu W, Chen J, Yu J, Gamble JR and McCaughan GW: Targeting the vasculature in hepatocellular carcinoma treatment: Starving versus normalizing blood supply. Clin Transl Gastroenterol 8: e98, 2017.

36. Morse MA, Sun W, Kim R, He AR, Abada PB, Mynderse M and Finn RS: The role of angiogenesis in hepatocellular carcinoma. Clin Cancer Res 25: 912-920, 2019.

37. Meng D, Frank AR and Jewell JL: mTOR signaling in stem and progenitor cells. Development 145: dev152595, 2018

38. Choe MH, Min JW, Jeon HB, Cho DH, Oh JS, Lee HG, Hwang SG, An S, Han YH and Kim JS: ERp57 modulates STAT3 activity in radioresistant laryngeal cancer cells and serves as a prognostic marker for laryngeal cancer. Oncotarget 6: 2654-2666, 2015.

39. Chung H, Cho H, Perry C, Song J, Ylaya K, Lee H and Kim JH: Downregulation of ERp57 expression is associated with poor prognosis in early-stage cervical cancer. Biomarkers 18: 573-579, 2013.

40. Shimoda T, Wada R, Kure S, Ishino K, Kudo M, Ohashi R, Fujita I, Uchida E, Yoshida $\mathrm{H}$ and Naito Z: Expression of protein disulfide isomerase A3 and its clinicopathological association in gastric cancer. Oncol Rep 41: 2265-2272, 2019.

41. Zou H, Wen C, Peng Z, Shao YY, Hu L, Li S, Li C and Zhou HH: P4HB and PDIA3 are associated with tumor progression and therapeutic outcome of diffuse gliomas. Oncol Rep 39: 501-510, 2018.

42. Hussmann M, Janke K, Kranz P, Neumann F, Mersch E, Baumann M, Goepelt K, Brockmeier U and Metzen E: Depletion of the thiol oxidoreductase ERp57 in tumor cells inhibits proliferation and increases sensitivity to ionizing radiation and chemotherapeutics. Oncotarget 6: 39247-39261, 2015.

This work is licensed under a Creative Commons Attribution-NonCommercial-NoDerivatives 4.0 International (CC BY-NC-ND 4.0) License. 